\title{
Animal models for panic disorder.
}

Rhayra Xavier do Carmo Silva ${ }^{1,2,3}$, Sueslene Prado Rocha ${ }^{4}$, Anderson Manoel Herculano $^{2}$, Monica Gomes Lima-Maximino ${ }^{4}$, Caio Maximino ${ }^{3,}{ }^{*}$

1 Programa de Pós-graduação em Neurociências e Biologia Celular, Universidade Federal do Pará - Marabá/PA, Brazil

2 Laboratório de Neurofarmacologia Experimental, Universidade Federal do Pará - Belém/PA, Brazil

3 Laboratório de Neurociências e Comportamento "Frederico Guilherme Graeff", Universidade Federal do Sul e Sudeste do Pará - Marabá/PA, Brazil

4 Laboratório de Neurofarmacologia e Biofísica, Universidade do Estado do Pará, Campus VIII - Marabá/PA, Brazil

* cmaximino@unifesspa.edu.br

\begin{abstract}
Panic disorder $(\mathrm{PD})$ is characterized by recurrent and uncontrollable panic attacks associated with behavioral changes and/or persistent anxiety due to the attacks. The development of behavioral models in animals is important for the understanding of the psychobiological and behavioral bases of $\mathrm{PD}$. The present article reviews the main models used in the current literature. Biobehavioral assays used in rats and mice include fear conditioning (which presents moderate predictive, face, and construct validities); the elevated T-maze (which presents good predictive validity, but low face and construct validities); electrical stimulation of the periaqueductal gray (which presents good face validity, but moderate construct validity); predator exposure models (which present good predictive and moderate construct validity); and

hypercapnia-induced responses (which present moderate construct validity). These three approaches seek coherence with theories on fear as a way to increase its translational potential; thus, while the elevated T-maze is supported by the Deakin/Graeff theory, the mouse defense test battery relies on the concept of defensive distance, and periaqueductal gray stimulation is based on the functional neuroanatomy of fear. Moreover, to higher or lower degree the three models are supported by an "etho-experimental" approach, with careful observation of animal behavior as a way of discriminating different defensive strategies that model different aspects of anxiety, fear, and panic. These assays can be used, in conjunction with independent variables that attempt to simulate the vulnerabilities and stressors which lead to panic attacks, to produce true models of PD. Finally, an alternative/complementary model is proposed that uses zebrafish alarm reaction to study this disorder.

Keywords: Panic disorder; Animal experimentation; Defensive behavior (Animal); Escape behavior (Animal)
\end{abstract}




\section{Introduction}

Panic disorder (PD) is characterized by recurrent and unexpected panic attacks that are associated with behavioral changes and/or persistent anticipatory anxiety due to these attacks (American Psychiatric Association, 2013). Panic attacks occur involuntarily and, although they have unknown causes, there is evidence that, for the majority of patients, moderate phobic or hypochondriac symptoms precede the attacks (Craske, Miller, Rotunda, \& Barlow, 1990; Fava, Grandi, \& Canestrari, 1988); after the first attack occurs, the individual often begins to worry about the possibility of the occurrence of new attacks, and this recurrent worry or anticipatory anxiety increases avoidance strategies, but the timing of its occurrence remains unpredictable. It was proposed, then, that panic attacks are "unpredictable" rather than "unexpected" (Barlow, 2002). Besides symptom phenomenology, PD differs from other anxiety disorders due to its particular pharmacological response (Klein, 1964, 1981) and, partially, due to the independent structure of genetic and environmental risk factors (Gratacòs et al., 2007).

Figure 1. Basic circuits involved in panic attacks, panic disorder, and normal fear. The "fear pathway" involves forebrain and midbrain circuits that converge onto the dorsal periaqueductal gray area (DPAG) to produce fear- and panic-like behavioral outputs. This system interacts with a "panic inhibition system", involving a central amygdala (CeA)-raphe (lwDR) circuit that leads to serotonin release in the DPAG, inhibiting panic-like responses through a direct and an indirect pathway. The panic inhibition system has acid-sensing neurons which decrease the activity of this system, decreasing the inhibition in the presence of hypercapnia or acidic $\mathrm{pH}$, and triggering a panic attack.

Abbreviations: $\mathrm{Cg}$ - cingulate cortex; BLA - basolateral amygdala; CeA - central amygdala; $\mathrm{MH}$ medial hypothalamus; DPAG dorsolateral periaqueductal gray area; lwDR - lateral wings of the dorsal raphe nucleus; 5-HT - serotonin; GABA $-\gamma$-aminoburytic acid; $\mathrm{CRF}$ - corticotropin releasing factor.

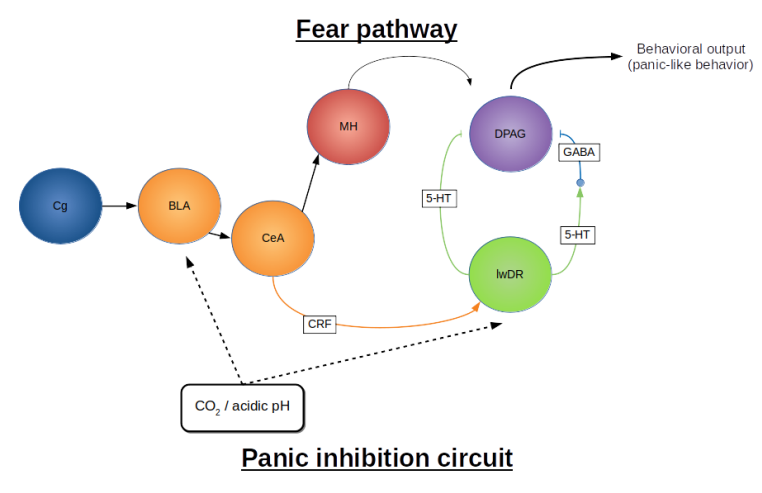

From a neuroanatomical point of view, PD presents important relationships with circuits underlying fear, including different amygdala nuclei, insular cortex, anterior cingulate cortex, and periaqueductal gray area (PAG) (Dresler et al., 2013; Gorman, Kent, Sullivan, \& Coplan, 2000; Graeff \& Del-Ben, 2008; Lovick, 2000; Sullivan, Coplan, Kent, \& Gorman, 1999). The mechanisms associated with unconditional and conditional responses compose a

fight/flight/freeze or aversive brain system that is represented by the medial hypothalamus, several amygdalar subnuclei, and the dorsal periaqueductal gray area (dPAG) (Brandão, Anseloni, Pandóssio, De Araújo, \& Castilho, 1999; Canteras, 2002; Cezario, Ribeiro-Barbosa, Baldo, \& Canteras, 2008; Gross \& Canteras, 2012; LeDoux, 2003; LeDoux \& Pine, 2016; Sukikara, Mota-ortiz, Baldo, Felício, \& Canteras, 2006). The electrical stimulation of these areas elicits a response pattern that characterize what is usually termed a defense reaction, and usually accompanies aversive subjective states characteristic of fear and anxiety (Brandão, Troncoso, de Souza Silva, \& Huston, 2003). The functioning of this aversive brain system can also be related to panic attacks. The electrical stimulation of dPAG elicits behaviours similar to the defense reaction as well as subjective and neurovegetative phenomena that resemble a panic attack not only in experimental animals, but also in humans (Graeff \& Del-Ben, 2008; Graeff, Silveira, Nogueira, Audi, \& Oliveira, 1993; Jenck, Moreau, \& Martin, 1995; Lovick, 2000).

An important concept that organizes theories derived from animal models is that of defensive direction and defensive distance (or predatory imminence continuum) (Deakin \& Graeff, 1991; Fanselow \& Lester, 1988; McNaughton \& Corr, 2004; McNaughton \& Zangrossi Jr, 2008; Perusini \& Fanselow, 2015). In general, it can be said that the more caudal portions of the system (especially the PAG) directly and immediately control defensive responses when the defensive distance is very small (proximal threat). As the distance increases, more complex defensive strategies emerge, and those responses are controlled by progressively more rostral structures, with the cingulate cortex representing the most distal threat. Defensive avoidance ("fear") is controlled by the amygdala and the anterior cingulate (Dresler et al., 2013; McNaughton \& Corr, 2004; Figure 1). Defensive approach ("anxiety") occurs when a strong drive conflicts with 
avoidance, triggering risk assessment behavior; these patterns are controlled by septo-hippocampal system and posterior cingulate (R. J. Blanchard \& Blanchard, 1988; Deakin \& Graeff, 1991; Gray \& McNaughton, 2003; LeDoux, 1998).

\section{Model validity and theories of panic disorder}

The representational nature of animal models demands that its adequacy as an hypothesis-generating device is satisfactory (Belzung \& Lemoine, 2011; Maximino \& van der Staay, 2019; van der Staay, 2006; Willner, 1986, 1991). This is the issue of validity. The act of modeling is the application of an independent variable - the simulation of a disorder in non-human animals based on knowledge of the etiology and mechanisms of the disease in humans - and the observation of a series of endpoints (dependent variables)(Maximino \& van der Staay, 2019; van der Staay, 2006; van der Staay \& Steckler, 2001). In the literature, sometimes tests are referred to as models, but most of the behavioral tests that are used in the field represent endpoints that are not model-specific. While screenings tests and biobehavioral assay need adequate validity at the predictive and face levels, "true" models rely on good construct validity (Maximino \& van der Staay, 2019). While many definitions of construct validity have been offered, its translational relevance is at least dependent on whether the model has a sound theoretical basis (Maximino \& van der Staay, 2019; McNaughton \& Zangrossi Jr, 2008; van der Staay, 2006; van der Staay, Arndt, \& Nordquist, 2009; van der Staay, Nordquist, $\&$ Arndt, 2017). As a result, a model is as good as is the theory underlying the disease it is targeting, and a true behavioral model is dependent on knowledge regarding etiology and on the neurobehavioral mechanisms underlying the disorder.

Predictive validity is usually reduced to pharmacological isomorphism, the congruence between clinical effects and drug effects in the animal tests. In the pharmacotherapy of PD, drugs with clinical efficacy include triazolobenzodiazepines, monoamine oxidase inhibitor, tricyclic antidepressants, and selective serotonin reuptake inhibitor (SSRIs)(Mitte, 2005). The triazolobenzodiazepines belong to the group of drugs called benzodiazepines that act by binding at the interface of the $\alpha$ and $\gamma$ subunits of the $\mathrm{GABA}_{\mathrm{A}}$ receptor. They are efficacious in the short-term treatment of panic disorder, but have largely been replaced by SSRIs as the first-line pharmacotherapy and are generally not regarded as appropriate for long-term therapy. The SSRIs were developed in the early 1970s. All SSRIs possess relatively high affinity for serotonin uptake sites. Imipramine is an antidepressant drug that can be used in the treatment of panic disorder, and belongs to the group of tricyclic antidepressants that act blocking both the serotonin transporter and the norepinephrine transporter. The role of imipramine was initially evidenced during a psychopharmacological experiment in which one group of patients referred for "tranquilizers", as they were very "anxious" and unable to respond to treatment with phenothiazines and sedatives, had the panic attacks ceased by tricyclic antidepressant imipramine treatment (Klein, 1964).

Moclobemide is a antidepressant drug that act as a reversible inhibitor of monoamine-oxidase-A, two comparative trials demonstrated moclobemide to be as efficacious as fluoxetine in patients suffering from panic disorder (Mitte, 2005). Pharmacologically isomorphic tests and models of PD, then, need to be sensitive to treatment with SSRIs, MAOis, tricyclic antidepressants, and triazolobenzodiazepines.

Models of PD, as will be shown, are associated with construct validity on at least two points: the first is the relationship between PD and theories of fear, and the second to specific theories of disordered fear responses in PD. Neurobehavioral theories of PD ans its relations to fear suggest that the disorder is due to disfunctions in circuits that control normal fear (Coplan \& Lydiard, 1998; Santos, D’Amico, \& Dierssen, 2015). Fear is thought to be organized at different levels of a circuit, organized in a rostrocaudal 
pathway, that includes amygdaloid subnuclei, the medial hypothalamus, and portions of the periaqueductal gray area (PAG)(Gross \& Canteras, 2012), receives inhibitory control from regions of the prefrontal cortex (Jovanovic \& Norrholm, 2011), and receives modulatory influence from monoamines such as serotonergic neurons from the raphe (Abrams, Johnson, Hollis, \& Lowry, 2004; Hale \& Lowry, 2011). Fear is qualitatively different from anxiety, as anxiety is oriented towards a potential threat, while fear is oriented towards a real (distal or proximal) threat; as a result, behavioral manifestations of fear tend towards escaping or avoiding the threat, while behavioral manifestations of anxiety tend towards cautious investigation and risk assessment (Corr, 2011; Gray \& McNaughton, 2003; McNaughton \& Corr, 2004; Perkins, Kemp, \& Corr, 2007; Perusini $\&$ Fanselow, 2015). Consistent with these theoretical propositions, generalized anxiety disorder is distinct from, e.g., panic disorder in phenomenology (worry vs. sense of imminent danger), neural bases, and neurochemistry - including responsiveness to serotonergic drugs (Barlow, 2002; Barlow, Chorpita, \& Turovsky, 1996; Klein, 1981).

Specific theories of PD have been proposed which include behavioral and neuronal events (Barlow, 2002; Fava \& Morton, 2009; Pilecki, Arentoft, \& McKay, 2011; Roth, Wilhelm, \& Pettit, 2005). The suffocation false alarm theory, first championed by Donald Klein (1993), proposes that spontaneous or unexpected panic attacks are triggered by a malfunctioning "monitor" in the brain stem that detects conditions that may lead to suffocation, including increased levels of carbon dioxide $\left(\mathrm{CO}_{2}\right)$. Using exploratory factor analysis, Meuret et al. (2006) showed that PD symptoms can be classified in dimensions, one of which includes cardio-respiratory symptoms (palpitations, shortness of breath, choking, chest pain, and numbness), somatic symptoms (sweating, trembling, nausea, chills/hot flashes, and dizziness), and cognitive symptoms (feelings of unreality, fear of going crazy, fear of losing control). Importantly, hierarchical multiple regression suggested that cardio-respiratory symptoms are the strongest predictors of panic severity, frequency of panic attacks, and agoraphobic avoidance, while cognitive symptoms are predictors of worry due to panic. It has been criticized because of its putative failure to identify abnormal physiological mechanisms underlying dyspnea during panic attacks (Roth et al., 2005). However, there has been considerable progress in that area, as physiological and psychobiological research advances. The ventral respiratory group of the brainstem has been identified as a site that detects $\mathrm{CO}_{2}$-associated pH changes (Mulkey et al., 2004; Nattie \& Li, 1996; Paul, Johnson, Shekhar \& Lowry, 2014), but responses in more rostral regions, including regions in the midbrain (tegmentum, parabrachial nucleus, and periaqueductal gray), hypothalamus, as well as limbic and paralimbic areas (amygdala and periamygdalar nuclei, cingulate, parahippocampal, and fusiform gyri, anterior insula) are reported in neuroimaging studies with healthy humans (Brannan et al., 2001), suggesting a distributed network involved in the affective representation and/or emotional regulation of breathing. In addition to this ventral hindbrain-limbic circuit, the role of other regions in pH-sensing has been suggested as well. A "panic inhibition system" in the lateral wings of the serotonergic dorsal raphe nucleus (that projects to the dorsal PAG) has been described (Paul et al., 2014) that is activated by hypercapnic stimuli (Johnson, Hollis, Moratalla, Lightman, \& Lowry, 2005). Using dynamic T1 $\rho$ relaxation imaging, which corresponds to an acidosis in the regions assessed, Magnotta et al. (2014) found a greater activity-evoked $\mathrm{T} 1 \rho$ response in the visual cortex of PD patients. From a molecular point of view, acidosis-related responses have been implicated as risk factors for PD (Quagliato, Freire, \& Nardi, 2018). The rs9915774 SNP of the ACCN1 gene (the human homologue of acid-sensing ion channel 2) has been found to be associated with PD in genome-wide association analysis (Gregersen et al., 2012). In a metanalysis of four studies on the relationship between rs685012 SNP of the ACCN2 gene, which codes the neuronal amiloride-sensitive cation channel 2, Quagliato et al. (2018) found that the 
$\mathrm{C}$ allele increases the risk of PD, with a moderate effect.

Originally a modification of Klein's model, Gorman's neuroanatomical theory

(Dresler et al., 2013; Gorman et al., 2000; Gorman, Liebowitz, Fyer, \& Stein, 1989) has high heuristic value for the development of translationally relevant animal models, and considerably good construct validity. The "revised model" postulates that panic attacks are analogous to conditioned fear responses, and are mediated by a fear network that is centered in the amygdaloid nuclei and its connections to the hippocampus, medial prefrontal cortex, hypothalamus, and periaqueductal gray area (Gorman et al., 2000). Increasing overall serotonergic neurotransmission would normalize the "abnormal sensitivity" of these circuits in patients with PD by inhibiting noradrenergic neurons in the locus coeruleus and reducing transmission to the PAG. Panic attacks can be triggered either by misinterpretation of visceral afferents (including $\mathrm{CO}_{2}$-associated $\mathrm{pH}$ changes) or by association of context with previously occurring panic attacks.

In parallel to this panic-eliciting circuit that is superimposed on the "fear" circuit, a "panic inhibition circuit" has been proposed (Paul et al., 2014). Normal functioning of this circuit leads to a "return to normal" when the threatening stimulus is no longer present, initiating cautious exploration and anxiety-like responses that inform the organism of the actual level of risk. Thus, hyperosmotic or hypercapnic stimuli activate acid-sensing channels in the basolateral amygdala, which leads to the release of corticotropin-releasing factor $(\mathrm{CRF})$ in the lateral wings of the dorsal raphe nucleus and in the ventrolateral PAG. The activation of $\mathrm{CRF}_{2}$ receptors in these regions elicits the release of serotonin in the dorsal PAG, which inhibit the fight/flight/freeze response system via a direct or an indirect pathway (Figure 1). Moreover, the serotonergic neurons of the dorsal raphe are also acid-sensitive, and its activation decreases PAG output (Johnson et al., 2005). In PD, this circuit is dysfunctional, and is no longer able to counteract the action of the fear circuit (Paul et al., 2014). This model relies on the Deakin/Graeff theory of the role of serotonin in anxiety and fear (Deakin \& Graeff, 1991; Graeff, Guimarães, de Andrade, \& Deakin, 1996).

Figure 2, Evidence-based causal model of PD. Early life experiences and anxious traits combine to cause Anxiety Sensitivity, a trait that describes a vulnerability to aversive bodily sensations, including the aversive respiratory experiences that lead to hypercapnia. When the individual experiences hypercapnia, an abnormal activation of the fear circuitry leads to catastrophic cognitions regarding threat and the imminence of death, as well as to the activation of the hypothalamus-pituitaryadrenal (HPA) axis. These catastrophic cognitions establish the occasion for strategic avoidance strategies that reduce the activation of the fear circuitry, but perpetuate PD by inducing recurrent worry or anticipatory anxiety, as well as agoraphobic avoidance. Based on Pilecki et al. (2011).
Pilecki et al.

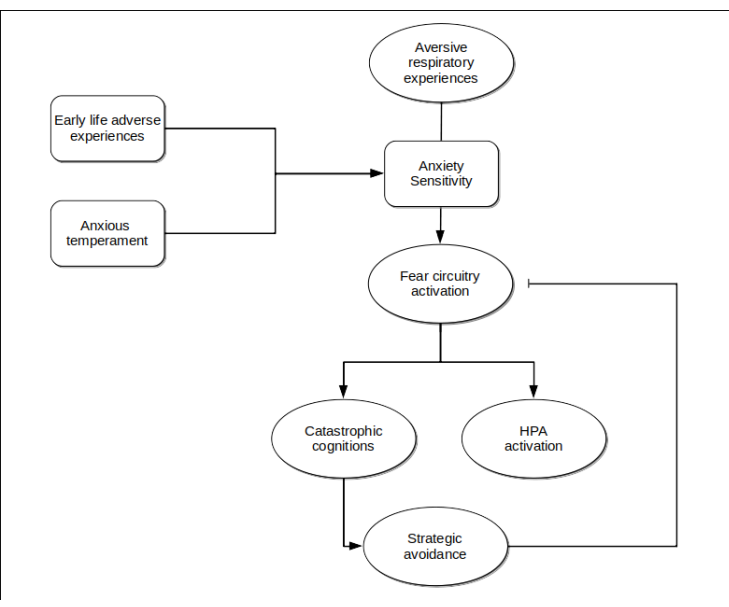

(2011) proposed a "causal model" of PD that is empirically supported by experimental evidence with PD patients, and is translationally relevant to animal models. In that model (Figure 2), predisposing factors for PD, including early life adverse experiences (Battaglia et al., 2009; Ogliari et al., 2010) and anxious temperament, are causally associated with susceptibility to panicogenic factors - Anxiety Sensitivity, the fear of bodily sensations (especially associated with $\mathrm{CO}_{2}$-associated $\mathrm{pH}$ changes), and the occurrence of aversive

respiratory experiences that lead to hypercapnia. The model is a diathesis-stress theory that attempts to explain why not all individuals panic when exposed to aversive respiratory experiences. Under these conditions, a panic attack occurs, leading to catastrophic cognitions regarding physical sensations as well as to the activation of the hypothalamus-pituitary-adrenal axis and of the fear circuit. Panic attacks cease when the individual successfully escapes or avoids the aversive situation, decreasing the activation of the fear circuit, which is accompanied by a reduction in anxious/fearful 
cognitions. Avoidance learning, however, can be an important factor in the development of the other symptoms of PD, including agoraphobia and/or other avoidance strategies. This model does not make direct reference to the neurocircuitry that is involved in responses, but tries to explain the role of early life adverse experiences in the development of PD; however, there is no reason to discard the circuitry that was described above.

\section{Endpoints for modeling panic disorder.}

The development of animal models for panic disorder is needed to establish the psychological and biological bases of this disorder, as well as to allow the development of novel therapeutics. Differently from models for generalized anxiety and biobehavioral tests for anxiety - that present a myriad of formats and exploit a diversity of different behaviors (Belzung \& Lemoine, 2011; Griebel \& Holmes, 2013) -, few paradigms explicitly model PD. Considering the behavioral difference between fear and anxiety, one should expect that appropriate endpoints for PD models would preferentially involve fear-like responses, and not anxiety. This distinction is based mainly on reference to the theoretical constructs that support the models (McNaughton \& Zangrossi Jr, 2008): while tests for anxiety use situations that impose approach/avoidance conflicts to animals - generating behavioral inhibition and risk assessment responses -, endpoints that are relevant for PD are based on defensive responses elicited by aversive stimuli or by the stimulation of specific brain regions (Moreira et al., 2013). In rodents, five main strategies have be used as endpoints to model panic attacks and/or PD: conditional fear responses (fear conditioning), escape in the elevated T-maze, antipredator behavior in the mouse defense test battery, escape and freezing responses elicited by the stimulation of the PAG or the medial hypothalamus, and hypercapnia-induced responses (Battaglia \& Ogliari, 2005; Moreira et al., 2013). The use of these endpoints is useful in itself - as biobehavioral assays to study the mechanisms of normal fear -, or as independent variables in a true model, in which specific manipulations (early life stress, genetic engineering) create "vulnerable organisms" (Belzung \& Lemoine, 2011) that show increased responses in these assays.

\subsection{Fear conditioning.}

Conditional fear responses have been widely used to establish fear-like responses and to elucidate the neural bases of these responses (LeDoux, 1998; Schafe, Nader, Blair, \& LeDoux, 2001). In fear conditioning, animals learn to associate a previously neutral stimulus (CS) with an aversive unconditioned stimulus (US, such as an electrical shock (LeDoux, 2003; Pavlov, 1927). In cued fear conditioning, the CS is explicit and reliably predicts the US, acting as a cue or signal; in contextual fear conditioning, animals display a defensive reaction (usually freezing) when introduced to a context (e.g., apparatus or chamber) in which they have been previously exposed to the US, and therefore the context represents a complex CS (Davis, Walker, Miles, \& Grillon, 2009). Typically, rats and mice display a initial activity burst to the footshock followed by freezing (LeDoux, 1998); reexposure to the CS in the absence of the US triggers memory retrieval, which initiates reconsolidation and extinction processes.

While fear conditioning is adaptive, and although conditioning accounts of panic disorder have been widely criticized, this process is an integral part of learning explanations of PD that attempt to incorporate some complexities of contemporary learning theory. Moreover, these learning accounts of PD provide a compelling explanation for the persistence of $\mathrm{PD}$, in spite of not always being able to explain the etiology of these disorders. Bouton et al. (2001) have argued that panic attacks are 
salient aversive USs during which feelings of anxiety and fear can be associated with external and/or interoceptive cues that are present during the attacks; subsequent exposure to these cues can trigger feelings of anticipatory anxiety, which in its turn can exacerbate the next panic attack.

Enhanced fear conditioning has been associated with gene variants in rodent orthologues of human PD risk genes. For example, Tmem132d, the human orthologue of which has been associated with PD in genome-wide association studies (A Erhardt et al., 2012; Angelika Erhardt et al., 2011; Howe et al., 2015; Mors et al., 2012; Otowa et al., 2012; Otowa, Tanii, et al., 2009; Otowa, Yoshida, et al., 2009), has been recently found to be associated in murine fear conditioning in a quantitative trait loci panel (Knoll, Halladay, Holmes, \& Levitt, 2016), and female mice with humanized COMT Val158Met polymorphism show reduced contextual fear, increased cued fear, and reduced extinction recall (Risbrough, Ji, Hauger, \& Zhou, 2014). A role for serotonin (5-HT) has also been suggested in conditional fear processes (Homberg, 2012): acute treatment with selective 5-HT reuptake inhibitors (SSRIs) facilitates fear conditioning, reduces contextual fear, and increases cued fear; $5-\mathrm{HT}_{1 \mathrm{~A}}$ receptors inhibit the acquisition and expression of contextual fear; $5-\mathrm{HT}_{2 \mathrm{~A}}$ receptors facilitate the consolidation of cued and contextual fear, while $5-\mathrm{HT}_{2 \mathrm{C}}$ receptors inhibit the retrieval of cued fear. Therefore, 5-HT appears to exert opposite effects on contextual and cued fear (Homberg, 2012). While consistent with the idea that contextual fear is more related to anxiety than fear, these results are actually opposed to what is observed in other models (Table 1 ).

Table 1. Effect of serotonergic drugs on putative models of fear and panic-like behavior. Abbreviations: ETM: Elevated T-mazed; MDTB: mouse defense test battery; PAG: periaqueductal gray area; SSRIs: selective serotonin reuptake inhibitors.

\begin{tabular}{l|llll}
\hline & SSRIs (acute) & $5-\mathrm{HT}_{1 \mathrm{~A}} \mathrm{R}$ & $5 \mathrm{HT}_{2 \mathrm{~A}} \mathrm{R}$ & $5-\mathrm{HT}_{2 \mathrm{C}} \mathrm{R}$ \\
\hline Cued fear & $\uparrow$ & $?$ & $\uparrow$ & $\downarrow$ \\
Contextual fear & $\downarrow$ & $\downarrow$ & $\uparrow$ & $?$ \\
ETM escape & $\downarrow$ & 0 & 0 & 0 \\
MDTB & 0 & 0 & 0 & 0 \\
PAG stimulation & $\downarrow$ & $\downarrow$ (local injection) & $\downarrow$ (local injection) & 0 (injection) \\
Zebrafish alarm reaction & $\downarrow$ & 0 & $\downarrow$ & $?$ \\
\hline
\end{tabular}

\subsection{Elevated T-maze.}

The elevated T-maze (ETM) is derived from the biobehavioral assay for anxiety that is most widely used contemporaneously - the elevated plus-maze -, and is explicitly based on the Deakin/Greaff hypothesis on the role of 5-HT on defensive behavior (Graeff, Ferreira Netto, \& Zangrossi Jr, 1998; Guimarães, Carobrez, \& Graeff, 2008; Zangrossi Jr \& Graeff, 2014). The ETM attempts to explicitly separate defensive behaviors that are evoked by motivational conflict (i.e., behavioral inhibition and risk assessment) from behaviors associated with fear states (i.e., escape). The apparatus consists in two open arms and one closed arm in a perpendicular configuration, elevated $50 \mathrm{~cm}$ from the floor (Viana, Tomaz, \& Graeff, 1994). In an ETM session, the rat executes two tasks: inhibitory avoidance and escape. First, the animal is transferred to the end of the closed arm, and the latency to leave this arm is measured; after $30 \mathrm{~s}$ intervals, the task is repeated twice, and increased latency to leave the closed arm is interpreted as the acquisition of inhibitory avoidance (Graeff et al., 1998). After this inhibitory avoidance task, the animal is positioned at the end of one of the open arms to measure the escape response (Viana et al., 1994). These two responses - inhibitory avoidance and escape recruit different neuronal circuits (Silveira, Zangrossi Jr, Viana, Silveira, \& Graeff, 2001) 
and present opposite 5-HTergic modulation (Graeff, Viana, \& Mora, 1996; Sena et al., 2003; Zangrossi Jr \& Graeff, 2014; Zangrossi Jr et al., 2001; Table 1). Inhibitory avoidance is interpreted as modeling anxiety-like responses, while escape is interpreted as modeling panic attacks (Graeff et al., 1998). Moreover, the assay appears to present good predictive validity for anxiolytic and panicolytic drugs (Graeff et al., 1998). An important critique to the model, however, is its low face validity: the association of escape from the open arm to panic attacks is tenuous, given that the escape observed in the ETM is slow, directed, and controlled - very different from escape responses which are observed in other models (Moreira et al., 2013). Moreover, while escape in the ETM appears to work as a biobehavioral assay - that is, as a tool to investigate normal fear responses, considering the involvement of structures which are associated with fear, as well as the predictive validity of the method -, its construct validity for PD is low, as it makes no explicit reference to etiology of to neurobehavioral mechanisms of panic (as opposed to normal fear).

\subsection{Mouse defense test battery.}

The mouse defense test battery (MDTB) evaluates the behavior of mice exposed to a natural predator, the rat, at different defensive distances (D. C. Blanchard, Griebel, \& Blanchard, 2001; Yang et al., 2004). The mouse is positioned in an oval runway, and an anesthetized rat is manipulated by the experimenter so that its approaches the mouse at a fixed velocity; when the rat approaches the mouse by about $1 \mathrm{~m}$, the mouse usually starts running, attempting to escape the aversive stimulus This assay explicitly assumes defensive distance (or predatory imminence continuum) - the psychological distance from the threat (R. J. Blanchard \& D. C. Blanchard, 1988; Fanselow \& Lester, 1988) as a central variable in decision making by the mouse. The model presents excellent predictive validity, since acute treatment with triazolobenzodiazepines and chronic treatment with imipramine, fluoxetine, and moclobemide decrease escape responses, while acute treatment with imipramine and fluoxetine or with panicogenic agents increase escape (D. C. Blanchard et al., 2001; R. J. Blanchard, Griebel, Henrie, \& D. C. Blanchard, 1997). Moreover, facilitating 5-HTergic neurotransmission in the periaqueductal gray inhibits escape in the MDTB (Pobbe, Zangrossi Jr, Blanchard, \& Blanchard, 2011), pointing to a participation of the "panic inhibition system" (Paul et al., 2014) in the control of normal responses in the assay. The assay presents as advantages the high ethological relevance, because it uses escape responses in an ecologically valid context and avoids using artificial stimuli such as electric shocks; moreover, the model allows the evaluation of two distinct responses - approach or escape the stimulus - that are predictive of anxiolytic or panicolytic effects, respectively (Moreira et al., 2013). Thus, as a biobehavioral assay, the MDTB presents good face and predictive validity.

\subsection{Stimulation of the dIPAG.}

The electrical or chemical stimulation of the dorsal periaqueductal grey (dPAG) evokes abrupt escape and/or freezing behavior and cardiovascular responses that is reminiscent of a panic attack (Beckett \& Marsden, 1995; Brandão, Zanoveli, Ruiz-Martinez, Oliveira, \& Landeira-Fernandez, 2008; Schenberg, 2010; Schenberg et al., 2014). Electrical currents with different amplitude, or different concentrations of glutamatergic or nitrergic drugs, are needed to induce freezing and escape (running and jumping) responses (de Oliveira, Del Bel, \& Guimarães, 2001; Schenberg, Bittencourt, Sudré, \& Vargas, 2002; Vianna, Graeff, Brandão, \& Landeira-Fernandez, 2001). Usually, lower concentrations or currents elicit alertness and escape, while higher concentrations or currents elicit a sequence that is characterized by alertness, freezing, and escape 
behavior interspersed with periods of tense immobility (Brandão et al., 2005, 2003, 2008). Similarly, disinhibiting the medial hypothalamus - a diencephalic structure that composes, along with the periaqueductal gray, the encephalic circuits which mediate fear responses and panic attacks (Canteras, 2002) - with GABAergic antagonists promote escape responses, hypertension, and tachycardia (DiMicco, Samuels, Zaretskaia, \& Zaretsky, 2002; Johnson, Lowry, Truitt, \& Shekhar, 2008; Johnson, Truitt, Fitz, Lowry, \& Shekhar, 2008). Both methods are based on observations on the effects of electrically stimulating these regions in humans, placing its construct validity in the similarity of neuronal circuits (Moreira et al., 2013). These tests also appear to present a good predictive validity, since panicolytic, but not anxiolytic drugs, alter behavior after stimulation (Johnson, Lowry, et al., 2008; Schenberg et al., 2002). However, from an etiological point of view, the induction of responses by direct stimulation of brain regions has a tenuous relation to spontaneous panic attacks observed in humans, and no references are made to how dysfunctions in these circuits lead to PD, or on the role of predisposing factors such as anxiety sensitivity, reducing construct validity.

In addition to freezing that is observed during dPAG stimulation, post-stimulation freezing is also observed (Brandão et al., 2008). Interrupting the electrical stimulation of the dPAG at the escape threshold elicits this freezing behavior, that is accompanied by activation of the laterodorsal nucleus of the thalamus, suggesting transfer of information to more rostral structures (Brandão et al., 2008). This led Brandão et al. (2008) to speculate that post-stimulation freezing is more related to risk assessment, as the animal freezes in order to better accumulate information on threat levels (see also Hagenaars, Oitzl, \& Roelofs, 2014); as a result, while stimulation-elicited freezing should be treated as a model for a panic attack, post-stimulation freezing would be a better model for anticipatory anxiety in PD (Brandão et al., 2008).

\subsection{Hypercapnia-induced behavioral and physiological responses.}

Hypersensitivity to $\mathrm{CO}_{2}$ shows considerable heuristic value for PD models (Battaglia, Ogliari, D'Amato, \& Kinkead, 2014), and is able to identify people at heightened risk for PD before the onset of the disorder (Coryell, Pine, Fyer, \& Klein, 2006). If these responses are predictive of the "core" symptoms of PD (panic attacks and avoidance), they can be understood as endophenotypes (Meuret et al., 2006). Using this information, methods were developed in which hypercapnia-induced behavioral and physiological responses are used in animals (Battaglia \& Ogliari, 2005; Battaglia et al., 2014; Schenberg et al., 2014). For example, slow infusion of potassium cyanide (KCN), an agent that induces cytotoxic hypoxia of the arterial chemoreceptor cells (Barros et al., 2002), induces defensive responses in rats that are similar to that observed with electrical or chemical stimulations of the dPAG (Schimitel et al., 2012), and sub-threshold doses of KCN facilitate responses elicited by electrical stimulation of the dPAG (Schimitel et al., 2012). Moreover, unilateral electrolytic lesions of the dPAG inhibit this response, suggesting that this structure is necessary for KCN-elicited responses. Unexpectedly, exposure to either $8 \%$ or $12 \% \mathrm{CO}_{2}$ induced respiratory alterations and producing signs of increased arousal in the open field (less exploratory behavior and appearance of exophthalmus), but actually attenuated dPAG-evoked responses, including freezing and flight (Schimitel et al., 2012). Since the KCN-evoked defensive behaviors were markedly facilitated by the previous exposure to $8 \%$ or $12 \%$ $\mathrm{CO}_{2}$, Schimitel et al. (2012) suggested the existence, in the PAG, of hypoxia-sensitive neurons that, when activated, could both precipitate a spontaneous panic attack and render the subject hyper-responsive to hypercapnia. c-Fos-like immunoreactivity experiments suggested a role for the dorsolateral and ventrolateral PAG, as well as of 
the lateral wings of the dorsal raphe nucleus (Berquin, Bodineau, Gros, \& Larnicol, 2000; Casanova, Contreras, Moya, Torrealba, \& Iturriaga, 2013; Hayward \& Von Reitzenstein, 2002; Johnson et al., 2011, 2005).

Interesting advances include modeling the differential sensitivity to hypoxia- or hypercapnia-induced responses in animals. This can be done by using sub-threshold concentrations; for example, rats injected with a sub-threshold concentration of lactate infusions - a substance which in trigger panic attacks in PD patients (Bourin, Malinge, \& Guitton, 1995) - show no overt behavioral changes, but display tachycardia, tachypnea, hypertension, and increased anxiety when GABA synthesis in the dorsomedial hypothalamus is chronically inhibited (Johnson, Lowry, et al., 2008; Johnson, Truitt, et al., 2008). These animals also show attenuated c-Fos-like responses in the lateral wings of the dorsal raphe nucleus (lwDRN) and the VLPAG (Johnson, Lowry, et al., 2008). Similarly, different rat strains show different sensitivities to $\mathrm{CO}_{2}$ inhalation (Winter, Ahlbrand, Naik, \& Sah, 2017), and behavioral extremes are an interesting source of variation to investigate vulnerabilities in disordered animals (van der Staay, 2006). Interestingly, $\mathrm{CO}_{2}$-sensitive strains show more serotonergic neurons in the lwDRN and the VLPAG and more adrenergic neurons in the locus coeruleus (Winter et al., 2017).

\subsection{Summary of behavioral endpoints in rodent tests.}

All five approaches are heavily based on face and predictive validity and its relations to theories on non-pathological fear, looking for coherence with theories on PD as a way to elevate the translational potential of the model; as such, while the ETM is grounded on the Deakin/Graeff theory, the MDTB is grounded mainly on the concept of defensive distance. Moreover, to a greater or lesser degree, the five approaches are sustained by an "etho-experimental" approach (R. J. Blanchard \& D. C. Blanchard, 1988), based on the careful observation of animal behavior as a way to discriminate between different defensive strategies that model different aspects of anxiety, fear, and panic. The five approaches present important advantages and disadvantages in modeling PD. Given the complexity of PD, it is to be expected that the use of a single test will not mimic all its aspects, considering the limitations related to the subjective aspects of the disorder (LeDoux \& Pine, 2016). Using different endpoints can mimic different aspects of the disorder, allowing better elucidation of the behavioral and neuropathological underpinnings of the disease. Ideally, various assays should be used to study the same disorder, including the use of different species (de Mooij-van Malsen, Vinkers, Peterse, Olivier, \& Kas, 2011; Kalueff, Ren-Patterson, LaPorte, \& Murphy, 2008; Kas, Gelegen, Schalkwyk, \& Collier, 2009; Keifer \& Summers, 2016; van der Staay, 2006).

\subsection{Complementary tests: The alarm response of zebrafish.}

Aiming to enrich the breadth of etho-experimental approaches traditionally made with rodents, the use of non-mammalian species has been proposed (Maximino et al., 2015). Among these, zebrafish (Danio rerio Hamilton 1822), a cyprinid fish widely used in genetics and developmental biology, has gained traction as a model organism in behavioral research (Gerlai, 2010; Kalueff et al., 2012; Norton \& Bally-Cuif, 2010; Rinkwitz, Mourrain, \& Becker, 2011; Shams, Rihel, Ortiz, \& Gerlai, 2018). Importantly for the study of fear and panic is the range of defensive responses that are observed in this species, among which the alarm reaction is relatively well-characterized and relevant for modeling PD (Maximino et al., 2018). This is a response that is initiated in the olfactory system by substances that are released by the damaged skin of conspecifics, and is characterized by dramatic and measurable changes in swimming patterns, as well as in well-defined physiological responses. The "alarm substance" 
produced by specialized skin cells ("club cells") and released after these cells are damaged is of unknown composition (Døving \& Lastein, 2009; Jesuthasan \& Mathuru, 2008), but it presents hypoxanthine 3-N-oxide and chondroitin fragments - substances which mimic part of the behavioral and physiological reactions (Mathuru et al., 2012; Parra, Adrian Jr, \& Gerlai, 2009). During exposure to this substance, an increase in shoal cohesion (Canzian, Fontana, Quadros, \& Rosemberg, 2017; Speedie \& Gerlai, 2008) and the initiation of patterns of erratic swimming followed by freezing (Mathuru et al., 2012; Quadros et al., 2016; Speedie \& Gerlai, 2008) is observed.

Differently from the behavior that is observed during exposure, behavior observed after exposure usually involves increased bottom dwelling associated with erratic swimming and freezing (Cachat et al., 2011; Egan et al., 2009), analgesia (Maximino, 2011), and increased dark preference (anxiety-like behavior) associated with erratic swimming, freezing, and thigmotaxis (Maximino, Lima, Costa, Guedes, \& Herculano, 2014). Moreover, the alarm substance also produces intense autonomic responses, with increased plasma levels of glucose, hemoglobin, norepinephrine, and epinephrine (Maximino et al., 2014), and a neuroendocrine stress response, with increased whole-body cortisol levels (Abreu, Giacomini, Koakoski, Piato, \& Barcellos, 2017; Schirmer, Jesuthasan, \& Mathuru, 2013). This array of behavioral and physiological adjustments simulate some important behavioral aspects and neurovegetative symptoms of panic attacks, lending significant face validity to the model. Moreover, the dissociation between responses produced during alarm substance exposure (erratic swimming and freezing, without increased bottom dwelling) and after exposure (increased bottom dwelling, erratic swimming, and freezing) is reminiscent of the distinction between freezing responses during and after the electrical stimulation of the dorsolateral column of the PAG in rats (Brandão et al., 2008), and could be further exploited as dependent variables in models for panic attacks and PD, respectively.

\section{Independent variables: The role of development and Anxiety Sensitivity.}

From the point of view of modeling theory, a true model ("simulation" sensu Wilner (1991)) is the application of a manipulation to observe neurobehavioral effects, grounded on the best theory on the etiology and mechanisms of the target disorder (Maximino \& van der Staay, 2019). Strictly speaking, then, there are very few true models for PD. These include genetic models based on knockout techniques, as well as diathesis-stress theory-based models.

A few genes have been shown, in knockout screens, to be involved in panic-like responses. Overexpression of the Ntrk3 gene, which codes for the TrkC receptor in mice, increases responsiveness in the MDTB, as well as the number of tyrosine hydroxylase-positive neurons in the locus coeruleus and substantia nigra (Dierssen et al., 2006). Overexpression also increases responsiveness to lactate infusions in the MDTB and in a predator avoidance test (Murtra et al., 2007). Conversely, knocking out the Htr1a gene, which encodes the $5-\mathrm{HT}_{1 \mathrm{~A}}$ receptor, increases responsiveness in a cued fear conditioning paradigm (Klemenhagen, Gordon, David, Hen, \& Gross, 2006). These results underline the potential of knockout approaches, widely documented in the last two decades, in unraveling the genetic vulnerabilities through animal models.

Early life adversities, including childhood parental loss and stressful life events occurring in childhood and adolescence, are associated with adult $\mathrm{CO}_{2}$ sensitivity and PD (Battaglia et al., 2009; Ogliari et al., 2010). Interestingly, Panksepp (1998) had already proposed that the circuits involved in what he calls a "PANIC" system, including opioidergic projections to the PAG, is associated with separation distress. Two key 
studies associate early interference with maternal care and CO2 hypersensitivity in rodents. Genest et al. (2007) exposed rat pups (postnatal days 3-13) to 3 h/day maternal separation and assessed hyperventilation during hypoxia and hypercapnia protocols during adulthood, as well as baseline differences in hypothalamus-pituitary-adrenal (HPA) axis activity. They showed that rats exposed to neonatal maternal separation showed higher hyperventilation during both hypoxia and hypercapnia and increased HPA axis activity. D'Amato et al. (2011) exposed mouse pups (postnatal days 1-4) to repeated cross-fostering (changing caregiver every $24 \mathrm{~h}$ ), observing no hyperventilation to hypoxia, but hypercapnia responses both during adolescence and adulthood, no effects on basal HPA axis activity, and higher avoidance of CO2-enriched environments. A combination of early-life stressors, hypercapnia responses, and the use of escape responses under hypercapnia (e.g., dPAG stimulation thresholds, or responses in the elevated T-maze) could provide an interesting diathesis-stress-based model for PD.

\section{Conclusions.}

The tests and animal models reviewed here present different advantages that can be exploited to discover the neurobiological and behavioral mechanisms associated with $\mathrm{PD}$, as well as the specific disadvantages that suggest the use of complementary approaches. These tests and models vary in terms of validity - for example, the face validity of the elevated T-maze is lower than the other presented models, but its relation to behavioral theories of fear is higher than the models involving electrical or chemical stimulation. Finally, the introduction of new models - including models with non-mammalian species, such as the use of alarm substance in Danio rerio - is an approach with great potential to amplify the field of investigation, testing novel psychobiological, behavioral, and developmental hypotheses on this disorder and associated factors. The field of animal modeling can only profit from the inclusion of these approaches in the roster of investigation strategies.

\section{Acknowledgments}

Part of the research reported was funded by Conselho Nacional de Desenvolvimento Científico e Tecnológico (CNPq/Brazil, grant no. 400726/2016-5).

\section{References}

Abrams, J. K., Johnson, P. L., Hollis, J. H., \& Lowry, C. A. (2004). Anatomic and functional topography of the dorsal raphe nucleus. Annals of the New York Academy of Sciences, 1018, 46-57. https://doi.org/10.1196/annals.1296.005

Abreu, M. S., Giacomini, A. C. V. V., Koakoski, G., Piato, A. L. S., \& Barcellos, L. J. G. (2017). Divergent effect of fluoxetine on the response to physical or chemical stressors in zebrafish. PeerJ, 5, e3330. https://doi.org/10.7717/peerj.3330

American Psychiatric Association. (2013). Diagnostic and Statistical Manual of Mental Disorders - Fifth Edition - DSM-5. (5 ${ }^{\text {th }}$ ed.) Washington: American Psychiatric Publishing.

Barlow, D. H. (2002). Anxiety and its disorders. The nature and treatment of anxiety and panic ( $2^{\text {nd }}$ ed.). New York, NY: The Guilford Press.

Barlow, D. H., Chorpita, B. F., \& Turovsky, J. (1996). Fear, panic, anxiety, and disorders of emotion. Nebraska Symposia on Motivation, 43, 251-328. 
Barros, R. C. H., Bonagamba, L. G. H., Okamoto-Canesin, R., de Oliveira, M., Branco, L. G. S., \& Machado, B. H. (2002). Cardiovascular responses to chemoreflex activation with potassium cyanide or hypoxic hypoxia in awake rats. Autonomic Neuroscience, 97, 110-115. https://doi.org/10.1016/S1566-0702(02)00050-4

Battaglia, M., \& Ogliari, A. (2005). Anxiety and panic: From human studies to animal research and back. Neuroscience \& Biobehavioral Reviews, 29, 169-179. https://doi.org/10.1016/j.neubiorev.2004.06.013

Battaglia, M., Ogliari, A., D’Amato, F., \& Kinkead, R. (2014). Early-life risk factors for panic and separation anxiety disorder: Insights and outstanding questions arising from human and animal studies of CO2 sensitivity. Neuroscience \& Biobehavioral Reviews, 46, 455-464. https://doi.org/10.1016/j.neubiorev.2014.04.005

Battaglia, M., Pesenti-Gritti, P., Medland, S. E., Ogliari, A., Tambs, K., \& Spatola, C. A. M. (2009). A genetically informed study of the association between childhood separation anxiety, sensitivity to $\mathrm{CO}_{2}$, panic disorder, and the effect of childhood parental loss. Archives of General Psychiatry, 66, 64. https://doi.org/10.1001/archgenpsychiatry.2008.513

Beckett, S., \& Marsden, C. A. (1995). Computer analysis and quantification of periaqueductal grey-induced defence behaviour. Journal of Neuroscience Methods, 58, $157-161$.

Belzung, C., \& Lemoine, M. (2011). Criteria of validity for animal models of psychiatric disorders: Focus on anxiety disorders and depression. Biology of Mood $\&$ Anxiety Disorders, 1, 9. https://doi.org/10.1186/2045-5380-1-9

Berquin, P., Bodineau, L., Gros, F., \& Larnicol, N. (2000). Brainstem and hypothalamic areas involved in respiratory chemoreflexes: A Fos study in adult rats. Brain Research, 857, 30-40. https://doi.org/10.1016/S0006-8993(99)02304-5

Blanchard, D. C., Griebel, G., \& Blanchard, R. J. (2001). Mouse defensive behaviors: Pharmacological and behavioral assays for anxiety and panic. Neuroscience E Biobehavioral Reviews, 25, 205-218.

Blanchard, R. J., \& Blanchard, D. C. (1988). Ethoexperimental approaches to the biology of emotion. Annual Review of Psychology, 39, 43-68.

Blanchard, R. J., Griebel, G., Henrie, J. A., \& Blanchard, D. C. (1997).

Differentiation of anxiolytic and panicolytic drugs by effects on rat and mouse defense test batteries. Neuroscience \& Biobehavioral Reviews, 21, 783-789.

Bourin, M., Malinge, M., \& Guitton, B. (1995). Provocative agents in panic disorder. Thérapie, 5, 301-306.

Bouton, M. E., Mineka, S., \& Barlow, D. H. (2001). A modern learning theory on the etiology of panic disorder. Psychological Review, 198, 4-32.

Brandão, M. L., Anseloni, V. Z., Pandóssio, J. E., De Araújo, J. E., \& Castilho, V. M. (1999). Neurochemical mechanisms of the defensive behavior in the dorsal midbrain. Neuroscience \& Biobehavioral Reviews, 23, 863-875.

Brandão, M. L., Borelli, K. G., Nobre, M. J., Santos, J. M., Albrechet-Souza, L., Oliveira, A. R., \& Martinez, R. C. (2005). Gabaergic regulation of the neural organization of fear in the midbrain tectum. Neuroscience $\&$ Biobehavioral Reviews, 29, 1299-1311. https://doi.org/10.1016/j.neubiorev.2005.04.013

Brandão, M. L., Troncoso, A. C., de Souza Silva, M. A., \& Huston, J. P. (2003). The relevance of neuronal substrates of defense in the midbrain tectum to anxiety and stress: empirical and conceptual considerations. European Journal of Pharmacology, 463, 225-233. https://doi.org/10.1016/S0014-2999(03)01284-6

Brandão, M. L., Zanoveli, J. M., Ruiz-Martinez, R. C., Oliveira, L. C., \& Landeira-Fernandez, J. (2008). Different patterns of freezing behavior organized in the periaqueductal gray of rats: Association with different types of anxiety. Behavioural Brain Research, 188, 1-13. https://doi.org/10.1016/j.bbr.2007.10.018 
Brannan, S., Liotti, M., Egan, G., Shade, R., Madden, L., Robillard, R., .. Fox, P. T. (2001). Neuroimaging of cerebral activations and deactivations associated with hypercapnia and hunger for air. Proceedings of the National Academy of Sciences, 98, 2029-2034. https://doi.org/10.1073/pnas.98.4.2029

Cachat, J., Stewart, A., Utterback, E., Hart, P., Gaikwad, S., Wong, K., .. Kalueff, A. V. (2011). Three-dimensional neurophenotyping of adult zebrafish behavior. PLoS ONE, 6, e17597. https://doi.org/10.1371/journal.pone.0017597

Canteras, N. S. (2002). The medial hypothalamic defensive system: Hodological organization and functional implications. Pharmacology, Biochemistry \& Behavior, 71, 481-491.

Canzian, J., Fontana, B. D., Quadros, V. A., \& Rosemberg, D. B. (2017). Conspecific alarm substance differently alters group behavior of zebrafish populations: Putative involvement of cholinergic and purinergic signaling in anxiety- and fear-like responses. Behavioural Brain Research, 320, 255-263. https://doi.org/10.1016/j.bbr.2016.12.018

Casanova, J. P., Contreras, M., Moya, E. A., Torrealba, F., \& Iturriaga, R. (2013). Effect of insular cortex inactivation on autonomic and behavioral responses to acute hypoxia in conscious rats. Behavioural Brain Research, 253, 60-67. https://doi.org/10.1016/j.bbr.2013.07.015

Cezario, A. F., Ribeiro-Barbosa, E. R., Baldo, M. V. C., \& Canteras, N. S. (2008). Hypothalamic sites responding to predator threats - The role of the dorsal premammillary nucleus in unconditioned and conditioned antipredatory defensive behavior. European Journal of Neuroscience, 28, 1003-1015. https://doi.org/10.1111/j.1460-9568.2008.06392.x

Coplan, J. D., \& Lydiard, R. B. (1998). Brain circuits in panic disorder. Biological Psychiatry, 44, 1264-1276. https://doi.org/10.1016/S0006-3223(98)00300-X

Corr, P. J. (2011). Anxiety: Splitting the phenomenological atom. Personality and Individual Differences, 50, 889-897. https://doi.org/10.1016/j.paid.2010.09.013

Coryell, W., Pine, D., Fyer, A., \& Klein, D. (2006). Anxiety responses to $\mathrm{CO}_{2}$ inhalation in subjects at high-risk for panic disorder. Journal of Affective Disorders, 92, 63-70. https://doi.org/10.1016/j.jad.2005.12.045

Craske, M. G., Miller, P. P., Rotunda, R., \& Barlow, D. H. (1990). A descriptive report of features of initial unexpected panic attacks in minimal and extensive avoiders. Behaviour Research and Therapy, 28, 395-400. https://doi.org/10.1016/0005-7967(90)90158-F

D’Amato, F. R., Zanettini, C., Lampis, V., Coccurello, R., Pascucci, T., Ventura, R., ... Battaglia, M. (2011). Unstable maternal environment, separation anxiety, and heightened $\mathrm{CO}_{2}$ sensitivity induced by gene-by-environment interplay. PLoS ONE, 6, e18637. https://doi.org/10.1371/journal.pone.0018637

Davis, M., Walker, D. L., Miles, L., \& Grillon, C. (2009). Phasic vs sustained fear in rats and humans: Role of the extended amygdala in fear vs anxiety.

Neuropsychopharmacology, 35, 105-135. https://doi.org/10.1038/npp.2009.109

de Mooij-van Malsen, A. J. G., Vinkers, C. H., Peterse, D. P., Olivier, B., \& Kas, M. J. H. (2011). Cross-species behavioural genetics: A starting point for unravelling the neurobiology of human psychiatric disorders. Progress in Neuro-Psychopharmacology $\&$ Biological Psychiatry, 35, 1383-1390.

https://doi.org/10.1016/j.pnpbp.2010.10.003

de Oliveira, R. M. W., Del Bel, E. A., \& Guimarães, F. S. (2001). Effects of excitatory amino acids and nitric oxide on flight behavior elicited from the dorsolateral periaqueductal gray. Neuroscience \& Biobehavioral Reviews, 25, 679-685. https://doi.org/10.1016/S0149-7634(01)00050-1

Deakin, J. F. W., \& Graeff, F. G. (1991). 5-HT and mechanisms of defense. Journal 
of Psychopharmacology, 5, 305-315.

Dierssen, M., Gratacòs, M., Sahún, I., Martín, M., Gallego, X., Amador-Arjona, A., ... Estivill, X. (2006). Transgenic mice overexpressing the full-length neurotrophin receptor TrkC exhibit increased catecholaminergic neuron density in specific brain areas and increased anxiety-like behavior and panic reaction. Neurobiology of Disease, 24, 403-418. https://doi.org/10.1016/j.nbd.2006.07.015

DiMicco, J. A., Samuels, B. C., Zaretskaia, M. V, \& Zaretsky, D. V. (2002). The dorsomedial hypothalamus and the response to stress. Part renaissance, part revolution. Pharmacology, Biochemistry \&6 Behavior, 71, 469-480.

Døving, K. B., \& Lastein, S. (2009). The alarm reaction in fishes - Odorants, modulations of responses, neural pathways. Annals of the New York Academy of Sciences, 1170, 413-423. https://doi.org/10.1111/j.1749-6632.2009.04111.x

Dresler, T., Guhn, A., Tupak, S. V., Ehlis, A. C., Herrmann, M. J., Fallgatter, A. J., ... Domschke, K. (2013). Revise the revised? New dimensions of the neuroanatomical hypothesis of panic disorder. Journal of Neural Transmission, 120, 3-29. https://doi.org/10.1007/s00702-012-0811-1

Egan, R. J., Bergner, C. L., Hart, P. C., Cachat, J. M., Canavello, P. R., Elegante, M. F., ... Kalueff, A. V. (2009). Understanding behavioral and physiological phenotypes of stress and anxiety in zebrafish. Behavioural Brain Research, 205, 38-44. https://doi.org/10.1016/j.bbr.2009.06.022

Erhardt, A., Akula, N., Schumacher, J., Czamara, D., Karbalai, N., Muller-Myhsok, B., ... Sasaki, T. (2012). Replication and meta-analysis of TMEM132D gene variants in panic disorder. Translational Psychiatry, 2, e156. https://doi.org/10.1038/tp.2012.85

Erhardt, A., Czibere, L., Roeske, D., Lucae, S., Unschuld, P. G., Ripke, S., ... Binder, E. B. (2011). TMEM132D: A new candidate for anxiety phenotypes - Evidence from human and mouse studies. Molecular Psychiatry, 16, 647-663. https://doi.org/10.1038/mp.2010.41

Fanselow, M. S., \& Lester, L. (1988). A functional behavioristic approach to aversively motivated behavior: Predatory imminence as a determinant of the topography of defensive behavior. In R. C. Bolles \& M. D. Beecher (Eds.), Evolution and Learning (pp. 185-211). Hillsdale: Erlbaum.

https://www.researchgate.net/publication/232466904_A_functional_ behavioristic_approach_to_aversively_motivated_behavior_Predatory_ imminence_as_a_determinant_of_the_topography_of_defensive_behavior

Fava, G. A., Grandi, S., \& Canestrari, R. (1988). Prodromal symptoms in panic disorder with agoraphobia. American Journal of Psychiatry, 145, 1564-1567.

Fava, L., \& Morton, J. (2009). Causal modeling of panic disorder theories. Clinical Psychology Review, 29, 623-637. https://doi.org/10.1016/j.cpr.2009.08.002

Genest, S.-E., Gulemetova, R., Laforest, S., Drolet, G., \& Kinkead, R. (2007). Neonatal maternal separation induces sex-specific augmentation of the hypercapnic ventilatory response in awake rat. Journal of Applied Physiology, 102, 1416-1421. https://doi.org/10.1152/japplphysiol.00454.2006

Gerlai, R. (2010). High-throughput behavioral screens: The first step towards finding genes involved in vertebrate brain function using zebrafish. Molecules, 15, 2609-2622. https://doi.org/10.3390/molecules15042609

Gorman, J. M., Kent, J. M., Sullivan, G. M., \& Coplan, J. D. (2000).

Neuroanatomical hypothesis of panic disorder, revised. American Journal of Psychiatry, 157, 493-505. https://doi.org/10.1176/appi.ajp.157.4.493

Gorman, J. M., Liebowitz, M. R., Fyer, A. J., \& Stein, J. (1989). A neuroanatomical hypothesis for panic disorder. American Journal of Psychiatry, 146, 148-161. https://doi.org/10.1176/ajp.146.2.148 
Graeff, F. G., \& Del-Ben, C. M. (2008). Neurobiology of panic disorder: From animal models to brain neuroimaging. Neuroscience \& Biobehavioral Reviews, 32, 1326-1335. https://doi.org/10.1016/j.neubiorev.2008.05.017

Graeff, F. G., Ferreira Netto, C., \& Zangrossi Jr, H. (1998). The elevated T-maze as an experimental model of anxiety. Neuroscience \& Biobehavioral Reviews, 23, 237-246. https://doi.org/10.1016/S0149-7634(98)00024-4

Graeff, F. G., Guimarães, F. S., de Andrade, T. G. C. S., \& Deakin, J. F. W. (1996). Role of 5-HT in stress, anxiety, and depression. Pharmacology, Biochemistry $\&$ Behavior, 54, 129-141.

Graeff, F. G., Silveira, M. C., Nogueira, R. L., Audi, E. A., \& Oliveira, R. M. (1993). Role of the amygdala and periaqueductal gray in anxiety and panic. Behavioural Brain Research, 58, 123-131.

Graeff, F. G., Viana, M. de B., \& Mora, P. O. (1996). Opposed regulation by dorsal raphe nucleus 5-HT pathways of two types of fear in the elevated T-maze.

Pharmacology, Biochemistry \& Behavior, 53, 171-177.

Gratacòs, M., Sahún, I., Gallego, X., Amador-Arjona, a, Estivill, X., \& Dierssen, M. (2007). Candidate genes for panic disorder: insight from human and mouse genetic studies. Genes, Brain, and Behavior, 6, 2-23.

https://doi.org/10.1111/j.1601-183X.2007.00318.x

Gray, J. A., \& McNaughton, N. (2003). The neuropsychology of anxiety. An enquiry into the functions of the septo-hippocampal system (2nd ed.). New York: Oxford University Press.

Gregersen, N., Dahl, H. A., Nyegaard, M., Hedemand, A., Als, T. D., Wang, A. G., ... Mors, O. (2012). A genome-wide study of panic disorder suggests the amiloride-sensitive cation channel 1 as a candidate gene. European Journal of Human Genetics, 20, 84-90. https://doi.org/10.1038/ejhg.2011.148

Griebel, G., \& Holmes, A. (2013). 50 years of hurdles and hope in anxiolytic drug discovery. Nature Reviews Drug Discovery, 12, 667-687.

https://doi.org/10.1038/nrd4075

Gross, C. T., \& Canteras, N. S. (2012). The many paths to fear. Nature Review Neuroscience, 13, 651-658. https://doi.org/10.1038/nrn3301

Guimarães, F. S., Carobrez, A. P., \& Graeff, F. G. (2008). Modulation of anxiety behaviors by 5 -HT-interacting drugs. In R. J. Blanchard, D. C. Blanchard, G. Griebel, \& D. J. Nutt (Eds.), Handbook of Anxiety and Fear (pp. 241-268). Amsterdam: Elsevier B. V.

Hagenaars, M. A., Oitzl, M., \& Roelofs, K. (2014). Updating freeze: Aligning animal and human research. Neuroscience \& Biobehavioral Reviews, 47, 165-176. https://doi.org/10.1016/j.neubiorev.2014.07.021

Hale, M. W., \& Lowry, C. A. (2011). Functional topography of midbrain and pontine serotonergic systems: Implications for synaptic regulation of serotonergic circuits. Psychopharmacology, 213, 243-264. https://doi.org/10.1007/s00213-010-2089-z

Hayward, L. F., \& Von Reitzenstein, M. (2002). c-Fos expression in the midbrain periaqueductal gray after chemoreceptor and baroreceptor activation. American Journal of Physiology-Heart and Circulatory Physiology, 283, H1975-H1984.

https://doi.org/10.1152/ajpheart.00300.2002

Homberg, J. R. (2012). Serotonergic modulation of conditioned fear. Scientifica, 2012, Article ID 821549. https://doi.org/10.6064/2012/821549

Howe, A., Buttenschøn, H., Bani-Fatemi, A., Maron, E., Otowa, T., Erhardt, A., ... Mors, O. (2015). Candidate genes in panic disorder: Meta-analyses of 23 common variants in major anxiogenic pathways. Molecular Psychiatry, 21, 665-679. https://doi.org/10.1038/mp.2015.138

Jenck, F., Moreau, J.-L., \& Martin, J. R. (1995). Dorsal periaqueductal 
gray-induced aversion as a simulation of panic anxiety: Elements of face and predictive validity. Psychological Research, 57, 181-191.

Jesuthasan, S. J., \& Mathuru, A. S. (2008). The alarm response in zebrafish: Innate fear in a vertebrate genetic model. Journal of Neurogenetics, 22, 211-229.

https://doi.org/10.1080/01677060802298475

Johnson, P. L., Fitz, S. D., Hollis, J. H., Moratalla, R., Lightman, S. L., Shekhar, A., \& Lowry, C. A. (2011). Induction of c-Fos in 'panic/defence'-related brain circuits following brief hypercarbic gas exposure. Journal of Psychopharmacology, 25, 26-36. https://doi.org/10.1177/0269881109353464

Johnson, P. L., Hollis, J. H., Moratalla, R., Lightman, S. L., \& Lowry, C. A. (2005). Acute hypercarbic gas exposure reveals functionally distinct subpopulations of serotonergic neurons in rats. Journal of Psychopharmacology, 19, 327-341. https://doi.org/10.1177/0269881105053281

Johnson, P. L., Lowry, C. A., Truitt, W., \& Shekhar, A. (2008). Disruption of GABAergic tone in the dorsomedial hypothalamus attenuates responses in a subset of serotonergic neurons in the dorsal raphe nucleus following lactate-induced panic. Journal of Psychopharmacology, 22, 642-652.

https://doi.org/10.1177/0269881107082900

Johnson, P. L., Truitt, W. A., Fitz, S. D., Lowry, C. A., \& Shekhar, A. (2008). Neural pathways underlying lactate-induced panic. Neuropsychopharmacology, 33, 2093-2107. https://doi.org/10.1038/sj.npp.1301621

Jovanovic, T., \& Norrholm, S. D. (2011). Neural mechanisms of impaired fear inhibition in posttraumatic stress disorder. Frontiers in Behavioral Neuroscience, 5, Article 44. https://doi.org/10.3389/fnbeh.2011.00044

Kalueff, A. V, Ren-Patterson, R. F., LaPorte, J. L., \& Murphy, D. L. (2008). Domain interplay concept in animal models of neuropsychiatric disorders: A new strategy for high-throughput neurophenotyping research. Behavioural Brain Research, 188, 243-249. https://doi.org/10.1016/j.bbr.2007.11.011

Kalueff, A. V, Stewart, A. M., Kyzar, E. J., Cachat, J., Gebhardt, M., Landsman, S., ... Zebrafish Neuroscience Research Consortium. (2012). Time to recognize zebrafish "affective" behavior. Behaviour, 149, 1019-1036.

https://doi.org/10.1163/1568539X-00003030 Kas, M. J. H., Gelegen, C., Schalkwyk, L. C., \& Collier, D. A. (2009). Interspecies comparisons of functional genetic variations and their implications in neuropsychiatry. American Journal of Medical Genetics, Part B: Neuropsychiatric Genetics, 150, 309-317.

https://doi.org/10.1002/ajmg.b.30815

Keifer, J., \& Summers, C. H. (2016). Putting the "biology" back into "neurobiology": The strength of diversity in animal model systems for neuroscience research. Frontiers in Systems Neuroscience, 10, Article 69. https://doi.org/10.3389/fnsys.2016.00069

Klein, D. F. (1964). Delineation of two drug-responsive anxiety syndromes. Psychopharmacologia, 5, 397-408.

Klein, D. F. (1981). Anxiety reconceptualized. In D. F. Klein \& J. G. Rabkin (Eds.), Anxiety: New Research and Changing Concepts (pp. 235-263). New York: Raven Press.

Klein, D. F. (1993). False suffocation alarms, spontaneous panics, and related conditions. Archives of General Psychiatry, 50, 306. https://doi.org/10.1001/archpsyc.1993.01820160076009

Klemenhagen, K. C., Gordon, J. A., David, D. J., Hen, R., \& Gross, C. T. (2006). Increased fear response to contextual cues in mice lacking the 5-HT1A receptor.

Neuropsychopharmacology, 31, 101-111. https://doi.org/10.1038/sj.npp.1300774

Knoll, A. T., Halladay, L. R., Holmes, A., \& Levitt, P. (2016). Quantitative trait loci and a novel genetic candidate for fear learning. Journal of Neuroscience, 36, 
6258-6268. https://doi.org/10.1523/JNEUROSCI.0177-16.2016

LeDoux, J. E. (1998). Fear and the brain: Where have we been, and where are we going? Biological Psychiatry, 44, 1229-138.

LeDoux, J. E. (2003). The emotional brain, fear, and the amygdala. Cellular and Molecular Neurobiology, 23, 727-738.

LeDoux, J. E., \& Pine, D. S. (2016). Using neuroscience to help understand fear and anxiety: A two-system framework. American Journal of Psychiatry, 173, 1083-1093. https://doi.org/10.1176/appi.ajp.2016.16030353

Lovick, T. A. (2000). Panic disorder-A malfunction of multiple transmitter control systems within the midbrain periaqueductal gray matter? Neuroscientist, 6, 48-59.

Magnotta, V. A., Johnson, C. P., Follmer, R., \& Wemmie, J. A. (2014). Functional T1 $\rho$ imaging in panic disorder. Biological Psychiatry, 75, 884-891.

https://doi.org/10.1016/j.biopsych.2013.09.008

Mathuru, A. S., Kibat, C., Cheong, W. F., Shui, G., Wenk, M. R., Friedrich, R. W., \& Jesuthasan, S. (2012). Chondroitin fragments are odorants that trigger fear behavior in fish. Current Biology, 22, 538-544.

https://doi.org/10.1016/j.cub.2012.01.061

Maximino, C. (2011). Modulation of nociceptive-like behavior in zebrafish (Danio rerio) by environmental stressors. Psychology \& Neuroscience, 4, 149-155.

https://doi.org/10.3922/j.psns.2011.1.017

Maximino, C., Lima, M. G., Costa, C. C., Guedes, I. M. L., \& Herculano, A. M. (2014). Fluoxetine and WAY 100,635 dissociate increases in scototaxis and analgesia induced by conspecific alarm substance in zebrafish (Danio rerio Hamilton 1822). Pharmacology, Biochemistry \& Behavior, 124C, 425-433.

https://doi.org/10.1016/j.pbb.2014.07.003

Maximino, C., Silva, R. X. do C., Campos, K. dos S., Oliveira, J. S. de, Rocha, S. P., Pyterson, M. P., ... Maximino, M. L. (2019). Sensory ecology of Ostariophysan alarm substances. Journal of Fish Biology. https://doi.org/10.1111/jfb.13844

Maximino, C., Silva, R. X. do C., da Silva, S. de N. S., Rodrigues, L. do S. D. S., Barbosa, H., de Carvalho, T. S., ... Herculano, A. M. (2015). Non-mammalian models in behavioral neuroscience: Consequences for biological psychiatry. Frontiers in Behavioral Neuroscience, 9, Article 233.

https://doi.org/10.3389/fnbeh.2015.00233

Maximino, C., \& van der Staay, F. J. (2019). Behavioral models in psychopathology: Epistemic and semantic considerations. Behavioral and Brain Functions, 15, Article 1. https://doi.org/10.1186/s12993-019-0152-4

McNaughton, N., \& Corr, P. J. (2004). A two-dimensional neuropsychology of defense: Fear/anxiety and defensive distance. Neuroscience $\&$ Biobehavioral Reviews, 28, 285-305. https://doi.org/10.1016/j.neubiorev.2004.03.005

McNaughton, N., \& Zangrossi Jr, H. (2008). Theoretical approaches to the modeling of anxiety in animals. In R. J. Blanchard, D. C. Blanchard, G. Griebel, \& D. J. Nutt (Eds.), Handbook of Anxiety and Fear (pp. 11-27). Amsterdam: Elsevier B. V.

Meuret, A. E., White, K. S., Ritz, T., Roth, W. T., Hofmann, S. G., \& Brown, T. A. (2006). Panic attack symptom dimensions and their relationship to illness characteristics in panic disorder. Journal of Psychiatric Research, 40, 520-527. https://doi.org/10.1016/j.jpsychires.2005.09.006

Mitte, K. (2005). A meta-analysis of the efficacy of psycho- and pharmacotherapy in panic disorder with and without agoraphobia. Journal of Affective Disorders, 88, 27-45. https://doi.org/10.1016/j.jad.2005.05.003

Moreira, F. A., Gobira, P. H., Viana, T. G., Vicente, M. A., Zangrossi Jr, H., \& Graeff, F. G. (2013). Modeling panic disorder in rodents. Cell \& Tissue Research, 354, 119-125. https://doi.org/10.1007/s00441-013-1610-1 
Mulkey, D. K., Stornetta, R. L., Weston, M. C., Simmons, J. R., Parker, A., Bayliss, D. A., \& Guyenet, P. G. (2004). Respiratory control by ventral surface chemoreceptor neurons in rats. Nature Neuroscience, 7, 1360-1369.

https://doi.org/10.1038/nn1357

Nattie, E. E., \& Li, A. (1996). Central chemoreception in the region of the ventral respiratory group in the rat. Journal of Applied Physiology, 81, 1987-1995.

https://doi.org/10.1152/jappl.1996.81.5.1987

Norton, W., \& Bally-cuif, L. (2010). Adult zebrafish as a model organism for behavioural genetics. BMC Neuroscience, 11, 90 .

https://doi.org/10.1186/1471-2202-11-90

Ogliari, A., Tambs, K., Harris, J. R., Scaini, S., Maffei, C., Reichborn-Kjennerud, T., \& Battaglia, M. (2010). The relationships between adverse events, early antecedents, and carbon dioxide reactivity as an intermediate phenotype of panic disorder.

Psychotherapy and Psychosomatics, 79, 48-55. https://doi.org/10.1159/000259417

Otowa, T., Kawamura, Y., Nishida, N., Sugaya, N., Koike, A., Yoshida, E., ... Sasaki, T. (2012). Meta-analysis of genome-wide association studies for panic disorder in the Japanese population. Translational Psychiatry, 2, e186.

https://doi.org/10.1038/tp.2012.89

Otowa, T., Tanii, H., Sugaya, N., Yoshida, E., Inoue, K., Yasuda, S., .. Sasaki, T. (2009). Replication of a genome-wide association study of panic disorder in a Japanese population. Journal of Human Genetics, 55, 91-96.

https://doi.org/10.1038/jhg.2009.127

Otowa, T., Yoshida, E., Sugaya, N., Yasuda, S., Nishimura, Y., Inoue, K., ... Okazaki, Y. (2009). Genome-wide association study of panic disorder in the Japanese population. Journal of Human Genetics, 54, 122-126. https://doi.org/10.1038/jhg.2008.17

Panksepp, J. (1998). Affective Neuroscience. The Foundations of Human and Animal Emotions. New York: Oxford University Press.

Parra, K. V, Adrian Jr, J. C., \& Gerlai, R. (2009). The synthetic substance hypoxanthine 3-N-oxide elicits alarm reactions in zebrafish (Danio rerio). Behavioural Brain Research, 205, 336-341. https://doi.org/10.1016/j.bbr.2009.06.037

Paul, E. D., Johnson, P. L., Shekhar, A., \& Lowry, C. A. (2014). The Deakin/Graeff hypothesis: Focus on serotonergic inhibition of panic. Neuroscience $\&$ Biobehavioral Reviews, 46, 379-396. https://doi.org/10.1016/j.neubiorev.2014.03.010

Pavlov, I. P. (1927). Conditioned reflexes. London: Oxford University Press.

Perkins, A. M., Kemp, S. E., \& Corr, P. J. (2007). Fear and anxiety as separable emotions: An investigation of the revised Reinforcement Sensitivity Theory of personality. Emotion, 7, 252-261. https://doi.org/10.1037/1528-3542.7.2.252

Perusini, J. N., \& Fanselow, M. S. (2015). Neurobehavioral perspectives on the distinction between fear and anxiety. Learning \& Memory, 22, 417-425. https://doi.org/10.1101/lm.039180.115

Pilecki, B., Arentoft, A., \& McKay, D. (2011). An evidence-based causal model of panic disorder. Journal of Anxiety Disorders, 25, 381-388.

https://doi.org/10.1016/j.janxdis.2010.10.013

Pobbe, R. L. H., Zangrossi Jr, H., Blanchard, D. C., \& Blanchard, R. J. (2011). Involvement of dorsal raphe nucleus and dorsal periaqueductal gray 5-HT receptors in the modulation of mouse defensive behaviors. European Neuropsychopharmacology, 21, 306-315. https://doi.org/10.1016/j.euroneuro.2010.05.004

Quadros, V. A., Silveira, A., Giuliani, G. S., Didonet, F., Silveira, A. S., Nunes, M. E., ... Rosemberg, D. B. (2016). Strain- and context-dependent behavioural responses of acute alarm substance exposure in zebrafish. Behavioural Processes, 122, 1-11. https://doi.org/10.1016/j.beproc.2015.10.014 
Quagliato, L. A., Freire, R. C., \& Nardi, A. E. (2018). The role of acid-sensitive ion channels in panic disorder: A systematic review of animal studies and meta-analysis of human studies. Translational Psychiatry, 8, 185.

https://doi.org/10.1038/s41398-018-0238-z

Rinkwitz, S., Mourrain, P., \& Becker, T. S. (2011). Zebrafish: An integrative system for neurogenomics and neurosciences. Progress in Neurobiology, 93, 231-243. https://doi.org/10.1016/j.pneurobio.2010.11.003

Risbrough, V., Ji, B., Hauger, R., \& Zhou, X. (2014). Generation and characterization of humanized mice carrying COMT158 Met/Val Alleles. Neuropsychopharmacology, 39, 1823-1832. https://doi.org/10.1038/npp.2014.29

Roth, W. T., Wilhelm, F. H., \& Pettit, D. (2005). Are current theories of panic falsifiable? Psychological Bulletin, 131, 171-192. https://doi.org/10.1037/0033-2909.131.2.171

Sahún, I., Gallego, X., Gratacòs, M., Murtra, P., Trullás, R., Maldonado, R., ... Dierssen, M. (2007). Differential responses to anxiogenic drugs in a mouse model of panic disorder as revealed by Fos immunocytochemistry in specific areas of the fear circuitry. Amino Acids, 33, 677-688. https://doi.org/10.1007/s00726-006-0464-1

Santos, M., D’Amico, D., \& Dierssen, M. (2015). From neural to genetic substrates of panic disorder: Insights from human and mouse studies. European Journal of Pharmacology, 759, 127-141. https://doi.org/10.1016/j.ejphar.2015.03.039

Schafe, G. E., Nader, K., Blair, H. T., \& LeDoux, J. E. (2001). Memory consolidation of Pavlovian fear conditioning: A cellular and molecular perspective. Trends in Neurosciences, 24, 540-546. https://doi.org/10.1016/S0166-2236(00)01969-X

Schenberg, L. C. (2010). Towards a translational model of panic attack. Psychology 6 Neuroscience, 3 9-37. http://dx.doi.org/10.3922/j.psns.2010.1.003

Schenberg, L. C., Bittencourt, A. S., Sudré, E. C. M., \& Vargas, L. C. (2002). Modeling panic attacks. Neuroscience \& Biobehavioral Reviews, 25, 647-659. https://doi.org/10.1016/S0149-7634(01)00060-4

Schenberg, L. C., Schimitel, F. G., Armini, R. D. S., Bernabé, C. S., Rosa, C. A., Tufik, S., ... Quintino-dos-Santos, J. W. (2014). Translational approach to studying panic disorder in rats: Hits and misses. Neuroscience 8 Biobehavioral Reviews, 46, 472-496. https://doi.org/10.1016/j.neubiorev.2014.10.002

Schimitel, F. G., Almeida, G. M., Pitol, D. N., Armini, R. de S., Tufik, S., \& Schenberg, L. C. (2012). Evidence of a suffocation alarm system within the periaqueductal gray matter of the rat. Neuroscience, 200, 59-73. https://doi.org/10.1016/j.neuroscience.2011.10.032

Schirmer, A., Jesuthasan, S., \& Mathuru, A. S. (2013). Tactile stimulation reduces fear in fish. Frontiers in Behavioral Neuroscience, 7, Article 167. https://doi.org/10.3389/fnbeh.2013.00167

Sena, L. M., Bueno, C., Pobbe, R. L. H., de Andrade, T. G. C. S., Zangrossi Jr, H., \& Viana, M. de B. (2003). The dorsal raphe nucleus exerts opposed control on generalized anxiety and panic-related defensive responses in rats. Behavioural Brain Research, 142, 125-133. https://doi.org/10.1016/S0166-4328(02)00399-6

Shams, S., Rihel, J., Ortiz, J. G., \& Gerlai, R. T. (2018). The zebrafish as a promising tool for modeling human brain disorders: A review based upon an IBNS Symposium. Neuroscience \& Biobehavioral Reviews, 75, 176-190. https://doi.org/10.1016/j.neubiorev.2017.09.002

Silveira, M. C. L., Zangrossi Jr, H., Viana, M. de B., Silveira, R., \& Graeff, F. G. (2001). Differential expression of Fos protein in the rat brain induced by performance of avoidance or escape in the elevated T-maze. Behavioural Brain Research, 126, 13-21. https ://doi.org/10.1016/S0166-4328(01)00233-9 
Speedie, N., \& Gerlai, R. (2008). Alarm substance induced behavioral responses in zebrafish (Danio rerio). Behavioural Brain Research, 188, 168-177.

https://doi.org/10.1016/j.bbr.2007.10.031

Sukikara, M. H., Mota-ortiz, S. R., Baldo, M. V. C., Felício, L. F., \& Canteras, N. S. (2006). A role for the periaqueductal gray in switching adaptive behavioral responses. Journal of Neuroscience, 26, 2583-2589.

https://doi .org/10.1523/JNEUROSCI .4279-05.2006

Sullivan, G. M., Coplan, J. D., Kent, J. M., \& Gorman, J. M. (1999). The noradrenergic system in pathological anxiety: A focus on panic with relevance to generalized anxiety and phobias. Biological Psychiatry, 46, 1205-128.

van der Staay, F. J. (2006). Animal models of behavioral dysfunctions: Basic concepts and classifications, and an evaluation strategy. Brain Research Reviews, 52, 131-159. https://doi.org/10.1016/j.brainresrev.2006.01.006

van der Staay, F. J., Arndt, S. S., \& Nordquist, R. E. (2009). Evaluation of animal models of neurobehavioral disorders. Behavioral and Brain Functions, 5, 11. https://doi.org/10.1186/1744-9081-5-11

van der Staay, F. J., Nordquist, R. E., \& Arndt, S. S. (2017). Large farm animal models of human neurobehavioral and psychiatric disorders: Methodological and practical considerations. In P. M. Conn (Ed.), Animal Models for the Study of Human Disease (2nd ed., pp. 71-100).

https://doi.org/10.1016/B978-0-12-809468-6.00003-6

van der Staay, F. J., \& Steckler, T. (2001). Behavioural phenotyping of mouse mutants. Behavioural Brain Research, 125, 3-12. https://doi.org/10.1016/S0166-4328(01)00278-9

Viana, M. de B., Tomaz, C., \& Graeff, F. G. (1994). The elevated T-maze: A new animal model of anxiety and memory. Pharmacology, Biochemistry 8 Behavior, 49, 549-554. https://doi.org/10.1016/0091-3057(94)90067-1

Vianna, D. M. L., Graeff, F. G., Brandão, M. L., \& Landeira-Fernandez, J. (2001). Defensive freezing evoked by electrical stimulation of the periaqueductal gray:

Comparison between dorsolateral and ventrolateral regions. Learning $\&$ Memory, 12, 4109-4112.

Willner, P. (1986). Validation criteria for animal models of human mental disorders: Learned helplessness as a paradigm case. Progress in Neuropsychopharmacology and Biological Psychiatry, 10, 677-690.

https://doi.org/10.1016/0278-5846(86)90051-5

Willner, P. (1991). Methods for assessing the validity of animal models of human psychopathology. In A. A. Boulton, G. B. Baker, \& M. T. Martin-Iverson (Eds.), Animal Models in Psychiatry (pp. 1-23). Clifton, NJ: Humana Press.

Winter, A., Ahlbrand, R., Naik, D., \& Sah, R. (2017). Differential behavioral sensitivity to carbon dioxide $\left(\mathrm{CO}_{2}\right)$ inhalation in rats. Neuroscience, 346, 423-433. https://doi.org/10.1016/j.neuroscience.2017.01.003

Yang, M., Augustsson, H., Markham, C. M., Hubbard, D. T., Webster, D., Wall, P. M., ... Blanchard, D. C. (2004). The rat exposure test: A model of mouse defensive behaviors. Physiology \& Behavior, 81, 465-473.

https://doi.org/10.1016/j.physbeh.2004.02.010

Zangrossi Jr, H., \& Graeff, F. G. (2014). Serotonin in anxiety and panic: Contributions of the elevated T-maze. Neuroscience $\&$ Biobehavioral Reviews, 46, 397-406. https://doi.org/10.1016/j.neubiorev.2014.03.007

Zangrossi Jr, H., Viana, M. de B., Zanoveli, J., Bueno, C., Nogueira, R. L., \& Graeff, F. G. (2001). Serotonergic regulation of inhibitory avoidance and one-way escape in the rat elevated T-maze. Neuroscience \& Biobehavioral Reviews, 25, 637-645. https://doi.org/10.1016/S0149-7634(01)00047-1 